\section{The General Meeting}

Virtually all the IOM's who attended EPS8 in Amsterdam must have been at the General Meeting which was held on the Wednesday morning (5September 1990). There being about 160 people present brought home the low percentage of members among the very healthy number of participants at the General Conference. The President, R.A. Ricci referred to this unhappy situation in his review of the state of EPS, and contrasted it to a number of initiatives which have brought encouraging results.

\section{The State of EPS}

With staff efficiency, the Society's organization and its activity classed as "good" and publications as "excellent", Professor Ricci singled out relationships with the Divisions as a major priority now that the Action Committees were maturing and assuming greater responsibilities, as witnessed by ACCAPI's work with the Associate Members and the industrial workshops, Physics and Society's east-west initiative and the Publications Committee's workshops.

The effort that had been devoted to relations with other bodies was yielding tangible results. EPS was now recognized by the Commission of the EC as an important consultative body for at least one major programme, by UNESCO as a partner in the ROSTENA initiative, and by the ESF as a participant in the recently established European Research Conferences. Nevertheless, changes in the east were prompting EPS to reappraise its policies and image now that the national societies in the region are interested in becoming more active partners. Professor Ricci responded to remarks made earlier at the conference about the nature of EPS by reminding us that while much of the Society's pioneering work to help eastern colleagues would not have been possible without the support of the national societies, EPS is nevertheless not a federation but represents the individual members and their societies.

The number of member societies was " $27+x$ ", the $x$ being maybe some of the new physical societies in the USSR. He referred to his visit with G. Thomas to Moscow in late August to discuss the situation with the representatives for the USSR (see page 177). The number of Associates now stood at 70 , down by 4 since 1988 : the number of IOM's had meanwhile increased from 3631 to 4292 .

\section{Future Strategy}

After describing the history, guidelines and recommendations of the task force set up after the Council meeting in Uppsala, Professor Ricci summarized the the overall financial situation which was later dealt with in more detail by the Treasurer.

Europhysics News would continue to be supported and adiabatically improved in line with decisions of the last two Council meetings. The national societies would still be urged to increase their financial support and in this respect, the letter from D.N.
Stacey in the September issue of the journal (which those present may have not read if they had not pick up a complimentary copy) outlined a straightforward way to solve the perennial problem of EPS finances. Much more cooperation and exchange between the east and the west was also envisaged and the Executive Committee had set up a task force chaired by O.G. Folberth to coordinate activities.

The President summed up with a list of the main points of action. They were: seek new, permanent sources of income; improve Divisional activities through stronger links with international bodies; increase the Associate Members' interest and support by coming up with some clever ideas, and cater for increased participation by national societies in the east. In general, enhance the prestige of EPS, boost the number of IOM's but, above all, have more young people participating.

\section{Red Shift}

The Treasurer, Ph. Choquard, in reviewing the past history of the Society's finances, highlighted the tendency for saw toothing between deficit and surplus with significant "red shift". He then detailed the budgetary impact of the decision to transfer the Executive Secretary and more of the Society's work to Budapest. A plan to do this had originally been work out in 1982 but rejected at the time as being unworkable. Since then much has changed. The only major reservation was that Gero Thomas's income and living conditions would suffer so it was imperative that the financial plan be based on his returning to Geneva in 2-3 years on a full salary. The other boundary conditions were a balanced budget in 1991 and continuation of Europhysics News towards the adiabatic regime.

The decision on the Secretariat's activities was based on the recommendation of the Executive Committee's task force. This group had met several times since March, twice with members of the staff in Geneva, before reporting back to the Committee. The Treasurer himself had also visited Budapest to meet with individuals and organizations that would probably be involved in the reconfiguration.

The Executive Committee had approved an updated budget for 1990 that gave a small surplus, and moving more of the Society's work to Budapest would show a larger surplus of SFR 60000 in 1991, the overall effect being a reduction of the accumulated deficit to about SFR 93000 . The improvement for 1990 was largely a result of the decision not to replace secretaries who had left the Secretariat.

\section{Budapest Expansion}

The estimated surplus for 1991 (SFR 60000 ) was based on having G. Thomas and two secretaries in Budapest with C. Bouldin (half-time for EPS), E. Thomas, P. Boswell and a junior secretary in Geneva. The staff agreed with the proposal and a scheme for sharing the work between Geneva and Budapest had been worked out. Expanding the Budapest operation has started and it will be fully operational by 1 January 1990. Details of where and who members should contact for specific items will be detailed in due course in Europhysics News. The basic scheme involves retaining publications activities, links with the Associates, promotional activities and some follow up of Action Committee decisions in Geneva but, in general, coordination with the governing bodies, Members, the Executive Committee, Action Committees and Divisions will be via Budapest.

$\mathrm{Ph}$. Choquard was confident that the Task Force's objective of eliminating the accumulated deficit in time for the 25th Anniversary of EPS three years from now will be met by transferring activities. What is perhaps more important is to ensure that the permanent income will then be such that we also celebrate Gero Thomas's return to Geneva. Income generating activities of all sorts are urgently needed and members are being urged to help. P. Boswell has been specifically asked to coordinate initiatives involving the Associates.

\section{Further Activities}

Before handing over the floor to the members, The Secretary, Maurice Jacob, reviewed the development of the Society's activities by noting that the expansion of Europhysics News was in the correct direction as it had carried articles with important impact and had helped to disseminate information about CEC programmes. However, he appealed once again for more news from the correspondents.

The three levels of the links with the Commission were described. We have the information about what is happening and how to interact. Next comes the provision of experts by the Divisions for review panels for the Science programme, an initiative which had met with a good response from both sides. Finally, there is EPS participation in organizing the CEC funded ERC's and similar meetings.

Forging new working bonds with other international bodies would continue. In particular, he had met officers of the recently constituted Association of Asia Pacific Physical Societies (AAPPS) that groups societies around the pacific rim and the Executive Committee will be considering ways in which relations can be developed.

\section{East-West Initiatives}

E.W.A. Lingeman was constrained to give but a brief summary of the recommendations contained in the report of the group that examined the east-west situation (see Europhysics News 21 (1990) 137). After emphasizing that the report gave a large amount of useful information about a very dynamic, rapidly changing situation, he urged members to request copies from their national societies. He outlined how each of the recommendations could possibly be implemented. It is now be up to the Task Force appointed by the Executive Commit- 
tee to coordinate initiatives through the Action Committees and other bodies.

\section{Members' Views On Finances}

J. Kaczer from Czechoslovakia remarked that the budget and statements in various reports gave the impression that non-convertible income was lost. In the case of his country this is not so because the agreement to pay $20 \%$ of contributions to EPS in hard currency has always been kept. The balance had also been paid and some of the funds used locally for specific items such as printing the address booklet. On a positive note, Czechoslovakia now has 100 IOM's up from 22 in 1972 and he thanked EPS for the financial help that allowed roughly 90 Czechoslovakian physicists to attend EPS-8 (only 35 made it to EPS-7).

Professor Kaczer was concerned about the future of the Czechoslovak society as government support through the Academy of Science may be in jeopardy, a feature that was highlighted in the east-west report. Moreover, it is the Academy who pays the $20 \%$ hard currency contribution.

As one possible strategy, D. Bek-Uzarov from Yugoslavia pointed out that EPS contributions from his country can be paid out of government funds for research so it is essential that EPS work to build support for this form of financing of research.

$D$. Sette raised the issue of the autonomy of the Divisions and central financing, a difficult and somewhat emotive issue. In reply to some specific proposals, Professor Ricci urged everyone to allow the Society to handle its internal finances informally and on the basis of mutual agreement.

A. Landesman thanked Ph. Choquard and the Task Force for their work in formulating a workable budget and Professor Ricci said he would be submitting the group's report to Council along with the Executive Committee's decisions.

\section{Members' Concerns}

P. Melville said he thought that there was considerable interest in EPS becoming some form of professional body able to grant a European qualification in physics as this would promote mobility. An applied physics division should be formed at the same time.

K.A. Müller told the assembled Members that Professor Ursu, a former President of both EPS and of the Ampere Group, was in detention in Romania and asked what EPS proposed to do about this. Professor Ricci said that he had received a telegramme from Professor Ursu's son, loan Ursu, telling him that his father was unable to accept an official invitation from the EPS President to attend the Conference. He would be replying shortly (see page 175).

With the audience for the next Plenary Session literally pressing its way in, the Meeting closed with the feeling that in spite of the considerable number of topics that it seemed necessary to consider, more time should have been left for discussion. Nonetheless, the Society clearly has momentum and now is not the time to falter.

\section{Physical Societies In The USSR}

Some 12 new physical societies have been founded recently in the USSR, but the only one having official recognition is the USSR Physical Society (or Soviet Physical Society) with S. Kapitza as President. Several of these societies are considering adherence to EPS. R.A. Ricci, President of EPS, and G. Thomas, the Executive Secretary, visited Moscow officially in late August to discuss the situation with Academician A.M. Prokhorov, President of the Department of General Physics and Astronomy of the Academy of Sciences. The aim was to work out how a satisfactory procedure can be established with which the new societies may apply for adherence to EPS.

The USSR Academy of Sciences is a founder member of EPS and Academician Prokhorov's proposal was that the Academy make an agreement with the Soviet Physical Society (SPS) for joint group membership that defined representation on the Council of EPS. As to the financial aspects, Academician Prokhorov clearly understood that EPS with its permanent, tight financial situation should not accept new members who cannot pay their fees. As a first step, he proposed to include in the agreement with the SPS an obligatory financial contribution. The Academy in any event would continue to pay in hard currency for its 2000 declared members. In view of the membership of the SPS, which is currently 6000 and is expected to increase to $20000-30000$ in a few years, the present contribution can no longer be considered sufficient. However, the level of the contribution will be discussed internally when establishing the agreement.

Regarding the various new physical societies, for example, those from the Baltic region, it is simply democratic that everybody can apply for EPS membership. However, the SPS should take the initiative by bringing together the Presidents of the different societies to discuss whether it would be possible to make additional agreements along the lines suggested for the one between the Academy and the SPS.

Meanwhile, applications to EPS from the new societies will be sent to the existing Group Member in the USSR which would make its recommendations before the applications are submitted to all the other Group Members, and to Council.

Academician Prokhorov's suggestions were discussed in a separate meeting with Professor Kapitza and other officers of the SPS. There was general agreement that joint representation in EPS of all the physical societies in the USSR would be a reasonable solution and Professor Kapitza undertook to make the necessary contacts. Special arrangements will probably have to be worked out for paying fees because it is at present almost impossible to obtain convertible funds in the country.

The complexity of the situation in the USSR is illustrated by the fact that in Moscow alone, besides the SPS, there is the Moscow Physical Society (which is to publish through IOPP a scientific journal in English with the editorial work done in the USSR), the Union of Soviet Physicists, Mathematicians and Astronomers (which has existed for many years and is under the auspices of the Academy) and the Moscow Union of Scientists (which groups together scientists in different fields). The futures of these various bodies depend upon political developments and any prognoses must be classified as purely speculative.

\section{G. Thomas} Executive Secretary

\section{Texas Tech University BUCY CHAIR IN PHYSICS}

Applications and nominations are invited for a new chair in physics (experimental particle physics) endowed by J. Fred Bucy and Odetta Greer Bucy.

The appointment will be at the rank of professor with tenure in the Department of Physics. Criteria for selection include distinguished research in experimental particle physics with an interest in Superconducting Super Collider collaboration and a commitment to physics teaching.

The Department of Physics is developing a program in particle physics to augment existing programs in atomic-molecular-optical physics, condensed matter, chemical physics, biophysics, nuclear physics, and pulsed power.

The department has 17 regular faculty members and approximately 50 graduate students who are pursuing Ph.D. and M.S. degrees in Physics or in Applied Physics.

Applicants should submit a resume, list of publications, and statement of research and teaching plans, as well as the name of five references to:

Professor Walter L. Borst, Chairman, Department of Physics,

Texas Tech University, Lubbock, Texas, USA, 79409-1051.

The deadline for receipt of application materials is March 1, 1991.

Texas Tech University is an Equal Opportunity/Affirmative Action Employer. 